\title{
An experimental study of the effects of electronic cigarette warnings on young adult nonsmokers' perceptions and behavioral intentions
}

\author{
Darren Mays ${ }^{1 *}$, Clayton Smith', Andrea C. Johnson ${ }^{1}$, Kenneth P. Tercyak ${ }^{1}$ and Raymond S. Niaura ${ }^{2}$
}

\begin{abstract}
Background: Electronic cigarette ("e-cigarette") manufacturers use warning labels on their advertising that vary widely in content and the U.S. Food and Drug Administration has issued a warning label requirement for e-cigarettes. There is limited data on the effects of these warnings on e-cigarette perceptions and other potential predictors of future tobacco use behavior in populations of interest to inform future regulatory requirements. This study examined the effects of e-cigarette warnings on perceptions of e-cigarettes and cigarettes and other cognitive precursors to tobacco use among young adult non-smokers.

Methods: Non-smoking young adults ages 18 to 30 years $(n=436)$ were recruited through an internet-based crowdsourcing platform for an online experiment. Participants completed pre-exposure measures of demographics, tobacco use, and other relevant constructs and were randomized to view 1 of 9 e-cigarette stimuli in a 3 ( $\mathrm{Ad} /$ Warning condition: Ad Only, Ad with Warning, Warning Only) x 3 (E-cigarette brand: Blu, MarkTen, Vuse) design. After viewing e-cigarette stimuli, participants reported perceptions of e-cigarettes and behavioral intentions to use e-cigarettes. Participants in the Ad Only and Ad with Warning conditions also completed a heat-mapping task assessing aspects of the ads that captured their attention. Then, participants were randomized to view cigarette ads from 1 of 3 major cigarette brands and reported perceptions of cigarettes and intentions to smoke cigarettes.
\end{abstract}

Results: Participants in the Warning Only condition reported significantly greater perceived harm and addictiveness of e-cigarettes and thoughts about not using e-cigarettes than the Ad Only and Ad with Warning conditions ( $p$ 's <.05). The Ad Only and Ad with Warning conditions did not differ on these outcomes. Participants in the Warning Only condition also reported the harms of e-cigarettes were closer to those of cigarettes than the Ad Only condition ( $p<.05)$, but neither differed from the Ad with Warning condition. Visual inspection of heat-mapping task data indicate warnings drew few participants' attention. There were no significant differences across study conditions on perceptions of cigarettes or intentions to smoke.

Conclusions: Text-based warning messages influenced young non-smokers' perceptions in a way that may dissuade e-cigarette use, but warnings appearing on advertisements had little impact.

Keywords: Electronic cigarettes, Warning labels, Young adults, Non-smokers

\footnotetext{
* Correspondence: dmm239@georgetown.edu

'Department of Oncology, Georgetown University Medical Center, Lombardi

Comprehensive Cancer Center, 3300 Whitehaven St NW Suite 4100,

Washington DC 20007, USA

Full list of author information is available at the end of the article
} 


\section{Background}

Population data indicate electronic cigarette (e-cigarette) use has increased in recent years in the U.S [1, 2]. From 2010 to 2013, lifetime e-cigarette use among adults increased from 3.3 to $8.5 \%$ [3]. Additionally, the available research indicates the prevalence of e-cigarette use is higher among young adults than all other adult age groups [3-5]. An analysis of U.S. population data collected in 2014 indicated $16.5 \%$ of young adults ages 18 to 24 had ever tried e-cigarettes but did not currently use them, and $5.2 \%$ were current (i.e., some days or every day) e-cigarette users [6]. E-cigarette advertising has also become more prominent in recent years with ads appearing online, in print media, and on television and radio [7]. E-cigarette ads often make implicit or explicit health-related claims (e.g., e-cigarettes are a safer alternative to cigarettes) and deploy strategies (e.g., celebrity endorsers) to enhance the appeal of the products [8]. Thus, advertising is likely a major factor contributing to e-cigarette use [8-10].

Experimental data show that e-cigarette ads affect perceptions of e-cigarettes and combustible cigarettes. E-cigarette ads produce urges to smoke among cigarette smokers and reduce former smokers' self-efficacy and intentions to remain abstinent [11]. Adult smokers are highly receptive to e-cigarette ads, and ads produce intentions to try e-cigarettes and elicit thoughts about smoking and quitting cigarettes [10]. E-cigarette ads have also been shown to prompt stronger intentions to use e-cigarettes in adolescents [12].

According to recent data young adults' exposure to ecigarette advertising is increasing [13] and research indicates young adults perceive e-cigarettes to be convenient, modern, and less harmful than cigarettes, themes that commonly appear in e-cigarette ads [14]. Although the prevalence of e-cigarette use among U.S. adult non-smokers remains low [6], a recent analysis of population data estimated that one quarter of U.S. young adults who do not use e-cigarettes are open to using them in the future, and more than one third of young adults who are open to using e-cigarettes are noncigarette smokers [15]. Recent longitudinal data also indicate young adulthood is a period when e-cigarette initiation occurs [16].

In May 2016, the Food and Drug Administration (FDA) issued a "deeming" rule bringing e-cigarettes under the FDA's regulatory authority $[17,18]$. The rule includes a warning label requirement for e-cigarette packaging and advertising reading: "WARNING: This product contains nicotine. Nicotine is an addictive chemical." The warning requirements will go into effect 24 months after publication of the final rule. Before this final rule was issued, several e-cigarette manufacturers have included warnings on their ads even though they were not required, which range from lengthy messages about potential harms to brief statements about addiction [19].

Warning labels communicating the potential risks of tobacco products are one component of a comprehensive approach to tobacco control. However, unlike research on cigarette warning labels, there is limited evidence on whether e-cigarette warning labels, including warnings currently used by manufacturers and the warning required by FDA, affect young adults' perceptions of e-cigarettes and intentions to use them. One recent experimental study conducted among U.S. young adults showed that warnings on e-cigarette television advertisements reduced cravings for cigarettes and ecigarettes among users of these products and reduced intentions to purchase e-cigarettes [20]. The study also showed that warnings conveying that some e-cigarettes are produced by cigarette companies increased perceptions that e-cigarettes are harmful, but reduced perceptions that e-cigarettes are addictive [20]. However, the study did not investigate the potential effects of the warning proposed by FDA in 2014, the warning now required in the final rule, or warnings used by manufacturers. Another recent experimental study showed that adult cigarette smokers and dual users of cigarettes and ecigarettes who were exposed to a warning label currently used by one e-cigarette manufacturer were more likely to perceive the product to be harmful, however the study did not examine potential effects of the warning among nonsmokers [21]. Additionally, given the evidence that young adult e-cigarette use is associated with use of combustible cigarettes, warnings on e-cigarette ads may affect perceptions of cigarettes and intentions to smoke [20], but this has not been investigated. The objective of this study was to examine the effects of warning labels on e-cigarette ads on young adult non-smokers' perceptions of e-cigarettes and behavioral intentions, and to investigate their effects on perceptions of combustible cigarettes and intentions to smoke.

\section{Methods}

\section{Setting and sample}

Participants were recruited through Amazon Mechanical Turk (AMT) [22], a crowdsourcing data collection platform used in similar studies of tobacco use [23-25] and other risk behaviors [26, 27]. After a brief description of the study, individuals residing in the U.S. who were interested in participating reviewed a complete study description with a link to a consent form and eligibility screener. Non-smokers ages 18 to 30 were eligible to participate. We focused on young adult non-smokers because this is a period when tobacco use initiation and transitions often occur, e-cigarette use is prevalent among young adults, and because young adults are 
targeted by tobacco industry advertising [28-30]. Age and cigarette smoking were assessed at screening, with those outside the target age range and those reporting smoking $\geq 100$ lifetime cigarettes and now smoking every day or some days [5] excluded. Eligible, consenting individuals proceeded to the online experiment. Participants completing all procedures were given a monetary credit through AMT.

\section{Procedures}

Study procedures occurred at a single time point through a series of steps. Participants reviewed a brief description of e-cigarettes to orient them to the study topic [5] and completed pre-exposure measures. Then, using an algorithm in the online survey participants were randomized to view 1 of 9 e-cigarette ad stimuli in a 3 (Ad/Warning condition: Ad Only, Ad with Warning, Warning Only) by 3 (Brand: Blu, MarkTen, Vuse) factorial experiment. Participants randomized to the Ad Only condition ( $n=144,33.0 \%)$ viewed an ad without a warning. Participants randomized to the Ad with Warning condition ( $n=147,33.7 \%)$ viewed an ad with a warning. Those randomized to the Warning Only $(n=145$, $33.3 \%)$ condition viewed a warning label alone, independent of any ad. Participants viewed an e-cigarette ad with or without a warning for the brand to which they were randomized (Blu $[n=138,31.6 \%]$, MarkTen $[n=$ $147,33.7 \%]$, or Vuse $[n=151,34.6 \%]$ ), or a warning label only. The warning in the Blu condition was the warning in FDA's 2014 proposed deeming rule, which is similar in contents to that of the final rule issued in 2016. The warning in the MarkTen condition was a lengthy warning about potential health risks used by this manufacturer on its ads at the time of the study. The warning in the Vuse condition was also a warning used by this manufacturer, a brief message about potential addiction. Print ads for each brand were obtained from a publicly available tobacco advertising database [31]. Ads were sized to identical dimensions and edited to remove minor differences for consistency across conditions (e.g., web site addresses). Warnings were displayed with consistent size, font, and placement across conditions. E-cigarette ad stimuli are available in Additional file 1. Participants viewed the e-cigarette ad stimuli for as long as they wished, and then completed e-cigarette outcome measures. While viewing the ads, participants in the Ad Only and Ad with Warning conditions also completed a heat map task where they were asked to identify up to 5 areas in the e-cigarette ads that attracted their attention by pointing their cursor and clicking on the areas of the e-cigarette ad image [32].

After completing e-cigarette outcome measures, participants were randomized to view a Camel $(n=150$, $34.4 \%)$, Marlboro $(n=140,32.1 \%)$, or Newport $(n=$
146, $33.5 \%)$ cigarette advertisement. We chose these brands because they are among the most widely advertised and top-selling cigarette brands in the U.S. We randomly assigned ads for three different cigarette brands to account for any potential impact of brand familiarity or preference within the design. Similar to ecigarette stimuli, cigarette ads were sized and presented consistently across conditions. After viewing cigarettes ads, participants completed cigarette outcome measures.

This study was approved as exempt by the Georgetown University Institutional Review Board. All participants provided informed consent.

\section{Measures \\ Pre-exposure measures}

Prior to the experimental exposure, demographics assessed included age, gender, race/ethnicity, household income, employment, and current college/university student status. Based on epidemiological items administered at screening [5], we created a variable categorizing participants as never smoking, trying cigarettes (i.e., tried smoking cigarettes but have not smoked 100 lifetime cigarettes), or experimenting (i.e., smoked 100 or more lifetime cigarettes but do not currently smoke on all or some days). A single item also measured whether participants had ever tried ecigarettes (yes/no) [5]. Another item measured exposure to e-cigarette advertising in magazines, on television, or convenience stores based on a five point scale [33, 34]. Four items also assessed past 30 day use of smokeless tobacco; cigars; little cigars and cigarillos; and waterpipe (hookah) tobacco use [5]. These were combined into a binary variable indicating use of any of these products in the past 30 days to characterize the sample.

\section{Outcome measures}

Outcome measures were based on a tobacco warning label science theoretical framework emphasizing consumer perceptions and behavioral intentions as cognitive antecedents to future behavior [35]. After exposure to the e-cigarette ad stimuli, perceived harms and addictiveness of e-cigarettes were measured with two items asking how harmful/addictive e-cigarettes are on a four point scale $(1=$ not at all, $2=$ slightly, $3=$ somewhat, $4=$ very harmful) $[23,36]$. Perceived harms and addictiveness of e-cigarettes relative to cigarettes were measured with two items asking participants whether e-cigarettes are less or more harmful/addictive than cigarettes [23, 36]. Response options were on five point scale $(1=$ much less, $2=$ less, 3 =about the same, $4=$ more, $5=$ much more) . Two items assessed thoughts about not using e-cigarettes on a 7-point scale [37]. Responses were averaged to create a summary score with higher values indicating more 
thoughts about not using e-cigarettes (Cronbach's $\alpha=$ $0.89)$. Behavioral intentions to use e-cigarettes were measured using an item asking how likely it is participants would use an e-cigarette in the next year based on a four point response scale ( $1=$ definitely will not, $4=$ definitely will) $[5,38,39]$.

After exposure to the cigarette ads, perceived harms and addictiveness of cigarettes were measured with two items with the same response scale as the e-cigarette items [23, 36]. Perceived harms and addictiveness of cigarettes relative to e-cigarettes were also measured with two items asking participants to indicate how harmful/ addictive cigarettes were to a person's health relative to e-cigarettes with response options similar to the ecigarette items $[23,36]$. Intentions to use cigarettes were measured with an item similar to the e-cigarettes measure, with response options on a four point scale $(1=$ definitely will not, $4=$ definitely will) $[5,38,39]$.

\section{Statistical analyses}

Bivariate analyses confirmed no participant characteristics differed $(p<.05)$ by experimental conditions. However, all multivariable analyses included covariates for prior e-cigarette use and e-cigarette advertising exposure to account for potential effects on study outcomes. Analysis of Covariance (ANCOVA) was used to examine differences in e-cigarette outcomes based on main effects for Ad/Warning condition, e-cigarette brand, and their interaction, adjusting for covariates noted above. Least-square means were examined for significant main and interaction effects, accounting for multiple comparisons using Tukey's adjustment. For cigarette outcomes, ANCOVA was used to examine differences based on main effects for Ad/Warning condition, e-cigarette brand, cigarette brand, and all two-way interactions. Ecigarette use, e-cigarette advertising exposure, and prior cigarette smoking were included as covariates.

\section{Results \\ Sample}

In total, 1,018 individuals responded to study eligibility screening questions, 436 of whom (42.8 \%) were eligible, randomized, and completed all study procedures. Among those who were ineligible $(n=582), 160(27.5 \%)$ were nonsmokers older than age 30, 177 (30.4\%) were smokers ages 18-30, and 245 (42.1\%) were smokers older than age 30. Participants averaged 25.0 years of age (SD 3.2 years), $55 \%$ were male, $81 \%$ were white, and $93 \%$ completed at least some college education (Table 1).

Perceptions of and behavioral intentions to use e-cigarettes There were significant main effects for Ad/Warning condition for perceived harms $\left(F=13.54, \eta^{2}=.060, p<.001\right)$
Table 1 Sample Characteristics $(n=436)$

\begin{tabular}{|c|c|}
\hline & Mean (SD) or \% (n) \\
\hline Age (M, SD) & $25.0(3.2)$ \\
\hline \multicolumn{2}{|l|}{ Gender $(\%, n)$} \\
\hline Male & $55.3 \%(241)$ \\
\hline Female & $44.7 \%$ (195) \\
\hline \multicolumn{2}{|l|}{ Race $(\%, n)$} \\
\hline Black/African American & $6.0 \%(26)$ \\
\hline White & $81.4 \%(354)$ \\
\hline Other & $12.7 \%(55)$ \\
\hline Hispanic ethnicity $(\%, \mathrm{n})$ & $10.6 \%(46)$ \\
\hline \multicolumn{2}{|l|}{ College/University student $(\%, \mathrm{n})$} \\
\hline Current student & $36.6 \%(159)$ \\
\hline Non-student & $63.5 \%(276)$ \\
\hline \multicolumn{2}{|l|}{ Education $(\%, n)$} \\
\hline$<$ High school & $1.2 \%(5)$ \\
\hline High school grad or GED & $6.4 \%(28)$ \\
\hline Some college & $46.7 \%$ (203) \\
\hline College degree or higher & $45.8 \%$ (199) \\
\hline \multicolumn{2}{|l|}{ Employment $(\%, \mathrm{n})$} \\
\hline Not employed & $25.2 \%(110)$ \\
\hline Full time employed & $52.1 \%(227)$ \\
\hline Part time employed & $22.7 \%(99)$ \\
\hline \multicolumn{2}{|l|}{ Annual household income $(\%, n)$} \\
\hline$<\$ 20,000$ & $21.6 \%(94)$ \\
\hline$\$ 20,001-\$ 35,000$ & $22.7 \%(99)$ \\
\hline$\$ 35,001-\$ 50,000$ & $21.3 \%(93)$ \\
\hline$\$ 50,001-\$ 75,000$ & $19.5 \%(85)$ \\
\hline$>\$ 75,000$ & $13.3 \%(58)$ \\
\hline Prefer not to say & $1.6 \%(7)$ \\
\hline \multicolumn{2}{|l|}{ Cigarette smoking $(\%, n)$} \\
\hline Never smoked & $40.1 \%(175)$ \\
\hline Tried smoking & $36.2 \%(158)$ \\
\hline Experimented & $23.6 \%(103)$ \\
\hline \multicolumn{2}{|l|}{$\begin{array}{l}\text { Past } 30 \text { day use of other tobacco } \\
\text { products }(\%, n)\end{array}$} \\
\hline Yes & $10.6 \%(46)$ \\
\hline No & $89.5 \%(390)$ \\
\hline \multicolumn{2}{|l|}{ Ever used e-cigarettes $(\%, n)$} \\
\hline Yes & $32.3 \%(141)$ \\
\hline No & $67.7 \%(295)$ \\
\hline $\begin{array}{l}\text { E-cigarette advertising exposure } \\
\text { (M, SD, range } 1 \text { to } 5 \text { ) }\end{array}$ & $3.1(0.78)$ \\
\hline
\end{tabular}

and addictiveness $\left(F=10.35, \eta^{2}=.047, p<.001\right)$ of ecigarettes (Table 2). Participants in the Warning Only condition reported greater perceived harms of e-cigarettes (M 3.02, SE 0.07) than the Ad Only (M 2.53, SE 0.07, 
Table 2 Analysis of covariance (ANCOVA) results for perceptions of e-cigarettes, thoughts about not using e-cigarettes, and behavioral intentions to use e-cigarettes

\begin{tabular}{|c|c|c|c|c|c|c|c|c|c|c|c|c|c|c|c|c|c|c|}
\hline & \multicolumn{3}{|c|}{$\begin{array}{l}\text { Perceived harms } \\
\text { of e-cigarettes }\end{array}$} & \multicolumn{3}{|c|}{$\begin{array}{l}\text { Perceived } \\
\text { addictiveness of } \\
\text { e-cigarettes }\end{array}$} & \multicolumn{3}{|c|}{$\begin{array}{l}\text { Perceived harms } \\
\text { of e-cigarettes } \\
\text { relative to } \\
\text { cigarettes }\end{array}$} & \multicolumn{3}{|c|}{$\begin{array}{l}\text { Perceived } \\
\text { addictiveness of } \\
\text { e-cigarettes rela- } \\
\text { tive to cigarettes }\end{array}$} & \multicolumn{3}{|c|}{$\begin{array}{l}\text { Thoughts about } \\
\text { not using e- } \\
\text { cigarettes }\end{array}$} & \multicolumn{3}{|c|}{$\begin{array}{l}\text { Intentions to use } \\
\text { e-cigarettes }\end{array}$} \\
\hline & $\mathrm{F}$ & $P$ & $\eta^{2}$ & $F$ & $P$ & $\eta^{2}$ & $F$ & $P$ & $\eta^{2}$ & $\bar{F}$ & $P$ & $\eta^{2}$ & $\bar{F}$ & $P$ & $\eta^{2}$ & $F$ & $P$ & $\eta^{2}$ \\
\hline \multicolumn{19}{|l|}{ Main effects } \\
\hline Ad/Warning condition & 13.54 & $<.001$ & .060 & 10.35 & $<.001$ & .047 & 3.12 & .045 & .015 & 7.11 & $<.001$ & .032 & 81.57 & $<.001$ & .278 & 1.80 & .167 & .008 \\
\hline E-cigarette brand & 1.28 & .279 & .006 & .20 & .817 & .001 & .39 & .677 & .002 & .95 & .389 & .004 & 1.50 & .224 & .007 & .68 & .505 & .003 \\
\hline \multicolumn{19}{|l|}{ Interaction Effect } \\
\hline $\mathrm{Ad} /$ Warning condition $\mathrm{x}$ & .24 & .918 & .002 & .83 & .508 & .008 & .21 & .933 & .002 & .59 & .670 & .006 & 2.29 & .059 & .021 & .47 & .758 & .004 \\
\hline \multicolumn{19}{|l|}{ E-cigarette brand } \\
\hline \multicolumn{19}{|l|}{ Covariates } \\
\hline $\begin{array}{l}\text { Ever used an } \\
\text { e-cigarette }\end{array}$ & 16.61 & $<.001$ & .038 & 12.32 & $<.001$ & .028 & 14.01 & $<.001$ & .032 & 9.87 & .002 & .023 & 15.09 & $<.001$ & .034 & 186.34 & $<.001$ & .305 \\
\hline $\begin{array}{l}\text { E-cigarette advertising } \\
\text { exposure }\end{array}$ & .58 & .445 & .001 & 1.36 & .244 & .003 & 2.18 & .141 & .005 & 1.19 & .275 & .003 & .06 & .810 & $<.001$ & .02 & .891 & $<.001$ \\
\hline
\end{tabular}

$p<.001)$ and Ad with Warning (M 2.74, SE 0.07, $p=.008)$ conditions (Fig. 1, Table 3). Participants in the Warning Only condition reported higher perceived addictiveness of e-cigarettes ( $M$ 3.25, SE 0.07) than the Ad Only ( $M$ 2.82, $S E$ 0.07, $p<.001$ ) and Ad with Warning (M 3.00, SE 0.07, $p=.02$ ) conditions (Fig. 1, Table 3).

For perceived harms of e-cigarettes relative to cigarettes, participants in the Warning Only condition $(M$ 2.24, $S E$.06) reported e-cigarettes to be closer to cigarettes in harm than the Ad Only condition ( $M$ 2.04, SE.06, $p=.055)$. There were no significant differences compared to the Ad with Warning condition ( $M$ 2.07, $S E$.06, Fig. 1, Table 3). Participants in the Warning Only condition reported e-cigarettes to be closer to cigarettes in addictiveness ( $M$ 2.77, SE .06) compared to the Ad Only $(M$ 2.46, SE .06, $p<.001)$ and Ad with Warning ( $M$ 2.59, SE .06, $p=.075)$ conditions. The Ad Only and Ad with Warning conditions did not differ $(p=.247$, Fig. 1, Table 3).
For thoughts about not using e-cigarettes there was a significant main effect for Ad/Warning condition ( $F=$ 81.57, $\eta^{2}=.278, p<.001$, Table 2). Participants in the Warning Only condition reported significantly more thoughts about not using e-cigarettes ( $M$ 5.50, SE 0.13) than the Ad Only $(M 3.16, S E 0.13, p<.001)$ and Ad with Warning ( $M$ 3.88, SE 0.13, $p<.001)$ conditions. Thoughts about not using e-cigarettes were significantly greater in the Ad with Warning condition than the Ad Only condition $(p<.001$, Fig. 1 , Table 3$)$. For intentions to use e-cigarettes there were no statistically significant effects (Table 2). There were no statistically significant main effects for e-cigarette brand or interaction effects between Ad/Warning condition and e-cigarette brand for any e-cigarette perceptions or behavioral intentions outcomes (Table 2).

Results of the heat map task are shown in Additional file 2. Visual inspection of these data indicates that overall few participants indicated the warnings on the

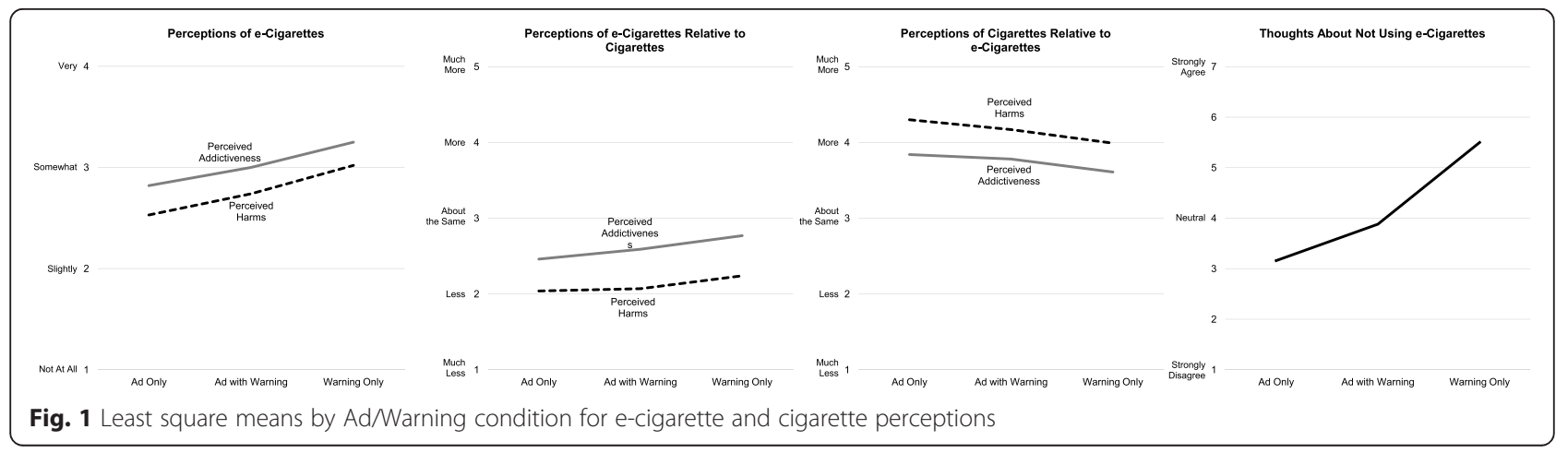


Table 3 Comparisons of least square means for perceptions of e-cigarettes, thoughts about not using e-cigarettes, and behavioral intentions to use e-cigarettes based on main effects for ad/warning condition and brand

\begin{tabular}{|c|c|c|c|c|c|c|c|c|c|c|c|c|}
\hline & \multicolumn{2}{|c|}{$\begin{array}{l}\text { Perceived harms } \\
\text { of e-cigarettes }\end{array}$} & \multicolumn{2}{|c|}{$\begin{array}{l}\text { Perceived } \\
\text { addictiveness } \\
\text { of e-cigarettes }\end{array}$} & \multicolumn{2}{|c|}{$\begin{array}{l}\text { Perceived harms } \\
\text { of e-cigarettes relative } \\
\text { to cigarettes }\end{array}$} & \multicolumn{2}{|c|}{$\begin{array}{l}\text { Perceived addictiveness } \\
\text { of e-cigarettes relative } \\
\text { to cigarettes }\end{array}$} & \multicolumn{2}{|c|}{$\begin{array}{l}\text { Thoughts about not } \\
\text { using e-cigarettes }\end{array}$} & \multicolumn{2}{|c|}{$\begin{array}{l}\text { Intentions to use } \\
\text { e-cigarettes }\end{array}$} \\
\hline & $\bar{M}$ & SE & $\bar{M}$ & SE & $\bar{M}$ & SE & $\mathrm{M}$ & SE & $\mathrm{M}$ & SE & $\mathrm{M}$ & SE \\
\hline \multicolumn{13}{|l|}{ Experimental condition } \\
\hline Ad only ${ }^{a}$ & $2.53^{\mathrm{C}}$ & .07 & $2.82^{C}$ & .07 & 2.04 & .06 & $2.46^{\mathrm{C}}$ & .06 & $3.16^{B, C}$ & .13 & 1.49 & .05 \\
\hline Ad with warning ${ }^{b}$ & $2.74^{C}$ & .07 & $3.00^{C}$ & .07 & 2.07 & .06 & 2.59 & .06 & $3.88^{\mathrm{A}, \mathrm{C}}$ & .13 & 1.58 & .05 \\
\hline Warning only ${ }^{c}$ & $3.02^{A, B}$ & .07 & $3.25^{A, B}$ & .07 & 2.24 & .06 & $2.77^{\mathrm{A}}$ & .06 & $5.50^{A, B}$ & .13 & 1.44 & .05 \\
\hline \multicolumn{13}{|l|}{ E-cigarette brand } \\
\hline $\mathrm{Blu}^{\mathrm{D}}$ & 2.75 & .07 & 3.05 & .07 & 2.08 & .06 & 2.64 & .06 & 4.24 & .13 & 1.52 & .06 \\
\hline MarkTen ${ }^{\mathrm{E}}$ & 2.85 & .07 & 3.04 & .07 & 2.16 & .06 & 2.54 & .06 & 4.30 & .13 & 1.45 & .05 \\
\hline Vuse $^{F}$ & 2.71 & .07 & 2.99 & .06 & 2.11 & .06 & 2.65 & .06 & 4.00 & .13 & 1.53 & .05 \\
\hline
\end{tabular}

Covariates included ever e-cigarette use and e-cigarette advertising exposure. Means with different superscript letters within a column differ significantly at $p<.05$ in pair-wise comparisons after Tukey's adjustment

ads drew their attention compared with ads' branded content.

Perceptions of and behavioral intentions to use cigarettes For perceived harms and addictiveness of cigarettes there were no significant effects (Table 4). For perceived harms of cigarettes relative to e-cigarettes, there was a significant main effect for Ad/Warning condition ( $F=$ 5.69, $\eta^{2}=.027, p=.004$, Table 4). Participants in the Warning Only condition reported cigarettes to be closer to e-cigarettes in perceived harm ( $M$ 3.99, SE 0.06) than the Ad Only condition ( $M$ 4.30, $S E 0.06, p=.003$, Fig. 1 ).
For perceived addictiveness of cigarettes relative to ecigarettes, the Ad/Warning condition main effect approached significance $\left(F=2.89, \eta^{2}=.014, p=.057\right.$, Table 4). There was a trend indicating that participants in the Warning Only condition reported cigarettes to be closer to e-cigarettes in perceived addictiveness $(M$ 3.61, SE 0.07) than the Ad Only condition ( $M$ 3.84, SE $0.07, p=.055$, Fig. 1, Table 5), however this difference was not statistically significant.

There was a significant main effect for cigarette brand for intentions to smoke cigarettes $\left(F=3.40, \eta^{2}=.014, p=\right.$ 0.034, Table 4). Participants viewing Newport ads reported

Table 4 Analysis of covariance (ANCOVA) results for perceptions of cigarettes and behavioral intentions to smoke

\begin{tabular}{|c|c|c|c|c|c|c|c|c|c|c|c|c|c|c|c|}
\hline & \multicolumn{3}{|c|}{$\begin{array}{l}\text { Perceived harms } \\
\text { of cigarettes }\end{array}$} & \multicolumn{3}{|c|}{$\begin{array}{l}\text { Perceived } \\
\text { addictiveness of } \\
\text { cigarettes }\end{array}$} & \multicolumn{3}{|c|}{$\begin{array}{l}\text { Perceived harms of } \\
\text { cigarettes relative to e- } \\
\text { cigarettes }\end{array}$} & \multicolumn{3}{|c|}{$\begin{array}{l}\text { Perceived } \\
\text { addictiveness of } \\
\text { cigarettes relative to e- } \\
\text { cigarettes }\end{array}$} & \multicolumn{3}{|c|}{$\begin{array}{l}\text { Intentions to use } \\
\text { cigarettes }\end{array}$} \\
\hline & $\bar{F}$ & $P$ & $\eta^{2}$ & $\bar{F}$ & $P$ & $\eta^{2}$ & $\bar{F}$ & $P$ & $\eta^{2}$ & $\mathrm{~F}$ & $P$ & $\eta^{2}$ & $\bar{F}$ & $P$ & $\eta^{2}$ \\
\hline \multicolumn{16}{|l|}{ Main effects } \\
\hline Ad/Warning condition & .82 & .441 & .004 & .26 & .774 & .001 & 5.69 & .004 & .027 & 2.89 & .057 & .014 & .85 & .428 & .003 \\
\hline E-cigarette brand & .35 & .702 & .002 & 1.32 & .267 & .006 & 1.30 & .274 & .006 & .47 & .623 & .002 & .80 & .449 & .003 \\
\hline Cigarette brand & .78 & .461 & .004 & .04 & .965 & .002 & .34 & .713 & .002 & .56 & .572 & .003 & 3.40 & .034 & .014 \\
\hline \multicolumn{16}{|l|}{ Interaction effect } \\
\hline Ad/Warning condition $x$ & .35 & .843 & .003 & .66 & .624 & .006 & 1.03 & .392 & .010 & .43 & .789 & .004 & 2.21 & .067 & .018 \\
\hline \multicolumn{16}{|l|}{ E-cigarette brand } \\
\hline Ad/Warning condition $x$ & .89 & .469 & .009 & .72 & .580 & .007 & 2.36 & .053 & .022 & 1.50 & .202 & .014 & .42 & .795 & .003 \\
\hline \multicolumn{16}{|l|}{ Cigarette brand } \\
\hline E-cigarette brand $x$ & .81 & .518 & .008 & .49 & .744 & .005 & .75 & .562 & .007 & .85 & .491 & .008 & .95 & .437 & .008 \\
\hline \multicolumn{16}{|l|}{ Cigarette brand } \\
\hline \multicolumn{16}{|l|}{ Covariates } \\
\hline Ever used an E-cigarette & .04 & .845 & .001 & .24 & .622 & $<.001$ & 15.90 & $<.001$ & .037 & 5.47 & .020 & .013 & 13.45 & $<.001$ & .027 \\
\hline E-cigarette Advertising exposure & .05 & .829 & .001 & 1.54 & .215 & .004 & .66 & .416 & .002 & .83 & .364 & .002 & 1.65 & .199 & .003 \\
\hline Cigarette smoking & .31 & .576 & $<.001$ & .45 & .502 & .001 & .04 & .832 & $<.001$ & .23 & .635 & $<.001$ & 10.24 & .002 & .021 \\
\hline
\end{tabular}


Table 5 Comparisons of least square means for perceptions of cigarettes and behavioral intentions to smoke cigarettes based on main effects for ad/warning condition, e-cigarette brand, and cigarette brand

\begin{tabular}{|c|c|c|c|c|c|c|c|c|c|c|}
\hline & \multicolumn{2}{|c|}{$\begin{array}{l}\text { Perceived harms of } \\
\text { cigarettes }\end{array}$} & \multicolumn{2}{|c|}{$\begin{array}{l}\text { Perceived addictiveness } \\
\text { of cigarettes }\end{array}$} & \multicolumn{2}{|c|}{$\begin{array}{l}\text { Perceived harms of cigarettes } \\
\text { relative to e-cigarettes }\end{array}$} & \multicolumn{2}{|c|}{$\begin{array}{l}\text { Perceived addictiveness } \\
\text { of cigarettes relative to } \\
\text { e-cigarettes }\end{array}$} & \multicolumn{2}{|c|}{$\begin{array}{l}\text { Intentions to smoke } \\
\text { cigarettes }\end{array}$} \\
\hline & $\bar{M}$ & SE & $\bar{M}$ & SE & $\bar{M}$ & SE & $\bar{M}$ & SE & $\bar{M}$ & SE \\
\hline \multicolumn{11}{|l|}{ Ad/Warning condition } \\
\hline Ad only ${ }^{a}$ & 3.89 & 0.04 & 3.81 & 0.04 & $4.30^{C}$ & 0.06 & 3.84 & 0.07 & 1.30 & 0.04 \\
\hline Ad with warning ${ }^{b}$ & 3.89 & 0.03 & 3.84 & 0.04 & 4.17 & 0.06 & 3.78 & 0.07 & 1.22 & 0.04 \\
\hline Warning only ${ }^{c}$ & 3.84 & 0.04 & 3.80 & 0.04 & $3.99^{\mathrm{A}}$ & 0.06 & 3.61 & 0.07 & 1.23 & 0.04 \\
\hline \multicolumn{11}{|l|}{ E-cigarette brand } \\
\hline $\mathrm{Blu}^{\mathrm{D}}$ & 3.87 & 0.04 & 3.77 & 0.04 & 4.24 & 0.07 & 3.78 & 0.07 & 1.26 & 0.04 \\
\hline MarkTen ${ }^{\mathrm{E}}$ & 3.86 & 0.03 & 3.80 & 0.04 & 4.10 & 0.06 & 3.76 & 0.07 & 1.21 & 0.04 \\
\hline Vuse $^{F}$ & 3.90 & 0.03 & 3.87 & 0.04 & 4.12 & 0.06 & 3.69 & 0.07 & 1.28 & 0.04 \\
\hline \multicolumn{11}{|l|}{ Cigarette brand } \\
\hline Camel $^{G}$ & 3.84 & 0.03 & 3.82 & 0.04 & 4.11 & 0.06 & 3.69 & 0.07 & $1.22^{1}$ & 0.04 \\
\hline Marlboro ${ }^{\mathrm{H}}$ & 3.90 & 0.04 & 3.81 & 0.04 & 4.17 & 0.06 & 3.75 & 0.07 & 1.19 & 0.04 \\
\hline Newport' & 3.87 & 0.03 & 3.81 & 0.04 & 4.18 & 0.06 & 3.79 & 0.07 & $1.34^{\mathrm{G}}$ & 0.04 \\
\hline
\end{tabular}

Note: Covariates included ever e-cigarette use, e-cigarette advertising exposure, and prior cigarette smoking. Means with different superscript letters within a column differ significantly at $p<.05$ in pair-wise comparisons after Tukey's adjustment for multiple comparisons.

higher intentions to smoke ( $M$ 1.34, SE 0.04) compared to Marlboro ads ( $M$ 1.19, SE 0.04, $p=0.037$, Table 5). There were no other significant effects for intentions to smoke (Table 4).

\section{Discussion}

This study provides preliminary experimental evidence of the effects of warning labels on e-cigarette advertisements among young adult non-smokers. This investigation builds from other recent experiments $[20,21]$ by examining the warning statement such as that required by FDA's deeming rule and warnings used by e-cigarette manufacturers within this population subgroup. Compared to ads with no warning labels and ads with warning labels, exposure to any of the three text-based e-cigarette warning labels tested independent of advertisements produced higher perceived harm and addictiveness of e-cigarettes and more thoughts about not using e-cigarettes. However, there were few differences in these outcomes between e-cigarette ads without warning labels and those that included warning labels. Self-report heat map data further supported the latter finding by indicating that branding elements on ecigarette ads captured participants' attention, but the warning labels did not. When examining perceived harm of cigarettes relative to e-cigarettes after participants viewed cigarette ads, e-cigarette warning labels viewed independent of ads produced perceptions that the harms of e-cigarettes are closer to those of cigarettes compared to e-cigarette ads without warning labels. There were no differences in any of the outcomes examined between FDA's proposed warning and those used on ads by two major e-cigarette manufacturers, however this finding should be interpreted cautiously because the experimental design did not fully isolate these effects because different warning messages were not randomized across brands. Finally, we also observed no impact across experimental conditions on intentions to use e-cigarettes or intentions to smoke cigarettes.

FDA's final deeming rule subjects e-cigarettes to many of the regulatory requirements of the Tobacco Control Act, including requiring warning labels on e-cigarette packaging and advertising. Our findings suggest textonly warnings for e-cigarettes may have limited impact on young adult non-smokers' perceptions of e-cigarettes when they appear on e-cigarette ads. One goal of warnings for e-cigarette ads stated in the regulations is to inform consumers, particularly young non-tobacco users, about the potential harms and addictiveness of ecigarettes [17, 18]. Our results indicate more effective strategies for designing e-cigarette warning label messaging may be needed to achieve this goal. Research on cigarette warning labels indicates factors such as the warning size, placement, message content, and features intended to draw visual attention affect consumer perceptions of tobacco products and related behavioral outcomes [35, 40-42]. With respect to warning message content, one recent experiment indicated warnings conveying that some e-cigarettes are produced by companies that make cigarettes may reduce craving to use cigarettes and e-cigarettes among young adult users of these products and reduce intentions to purchase ecigarettes among young adult smokers and non-smokers [20]. Otherwise, there is currently limited evidence on 
whether such features of e-cigarette warnings could enhance their public health impact, and research in this area will be important to inform potential future ecigarette regulatory requirements.

There has been speculation as to why e-cigarette manufacturers include warning labels on their advertisements prior to any regulatory requirements in the U.S., and before concrete evidence on the potential harms of long-term e-cigarette use is available. Manufacturers may do so to reduce their legal liability in the event products pose harms, and to attempt to develop a reputation of honesty and openness about the potential harms of their products [43]. However, the absence of regulations for e-cigarette advertisements until the recently published rule has meant that manufacturers have been free to test different warning messages to determine how they may affect their ads among consumers. Warnings used by manufacturers range widely, and this study attempted to capture the effects of different types of warnings used. A recent experimental investigation of the MarkTen warning label examined in this study showed that adult smokers and dual users of cigarettes and e-cigarettes notice the warning label, and those exposed to the warning were more likely to report that MarkTen e-cigarettes are harmful to health [21]. Our findings indicate the warnings used on ads for two major e-cigarette brands (MarkTen and Vuse), whose parent companies are also among the largest international cigarette companies (Altria, Inc., and Reynolds American, Inc., respectively), may have little effect among young adult non-smokers.

We also observed no significant differences across experimental conditions in behavioral intentions outcomes, which could be because a single brief exposure to ecigarette ads and warning labels is insufficient [23] or due to limited interest in using these products among young non-smokers $[3,6]$. Indeed, results of one recent study indicate that a small number of non-smokers included in the study indicated intentions to try ecigarettes after they were exposed to a series of ecigarette advertisements [44]. Our findings, along with the existing published research, indicate prospective studies with repeated exposures to e-cigarette warnings and that examine differences in their effects between young smokers and non-smokers will advance our understanding of these issues and inform potential future regulatory decisions.

The findings of this study should be interpreted in light of important limitations. All data are self-report and subject to potential reporting biases, and the online convenience sample limits generalizability of the findings. The study was conducted in a convenience sample recruited through an online data collection platform, limiting the potential generalizability of the findings to broader populations (e.g., those without internet access). We focused on young adult non-smokers based on the evidence that this is a population where e-cigarette use may occur, but future studies are needed to understand the impact of e-cigarette warning labels in other populations. Our study outcomes focused on perceptions and behavioral intentions and were assessed using primarily single item measures after a brief exposure to the experimental stimuli. This experimental approach, while informative, may not provide the ability to detect small changes in cognitive outcomes and prevents testing of potential mediation effects, such as whether changes in cognitive perceptions of e-cigarettes based on exposure to warning labels may impact behavioral outcomes. Additionally, in the experimental design we chose to match e-cigarette warnings with ads for a single e-cigarette brand (e.g., lengthy warning appeared only on MarkTen ads, FDA proposed warning appeared only on Blu ads). It is possible this may have affected our results, and in future experimental studies this could be addressed by randomizing different warnings of interest across brands. Also, participants randomized to the Ad Only and Ad with Warning conditions completed an additional heat mapping task, and it is unclear if this may have affected comparisons of outcomes between these two groups and the Warning Only condition. Finally, prior to the experimental exposure we measured lifetime ecigarette use with a single, brief item and used this as a covariate in analyses. Use of more granular measures of prior and current e-cigarette use in future studies can help to discern whether the potential effects of e-cigarette ads and warning labels may differ based on the extent of previous e-cigarette use and/or current e-cigarette use.

\section{Conclusions}

Despite these limitations, the results indicate the ecigarette warning required by FDA and warning labels used by e-cigarette manufacturers are not likely to have much impact among young adult non-smokers when they appear on e-cigarette ads. Future tobacco regulatory research can build from this study by using prospective methods to examine potential changes in e-cigarette perceptions and behavioral intentions with repeated exposures to warning labels, broadening the focus to other populations of interest to FDA regulatory decisions (e.g., young adult smokers), and examining whether alternative strategies to designing e-cigarette warnings may enhance their impact. This line of investigation will be important to inform FDA tobacco regulatory decision-making since e-cigarettes are now subject to the requirements of the Tobacco Control Act, including required warning labels for e-cigarette advertisements. 


\section{Additional files}

Additional file 1: E-cigarette advertising stimuli. (DOCX $5187 \mathrm{~kb}$ )

Additional file 2: Results of heat-mapping task assessing visual attention to e-cigarette advertising stimuli. (DOCX $735 \mathrm{~kb}$ )

\section{Abbreviations}

E-cigarette, electronic cigarette; FDA, Food and Drug Administration

\section{Acknowledgments}

The authors thank Sarah Murphy for assistance with the study.

\section{Funding}

This study was supported by the National Institutes of Health $(\mathrm{NIH})$ and the Food and Drug Administration (FDA) Center for Tobacco Products under $\mathrm{NIH}$ grant number K07CA172217. This work was also supported in part by the Georgetown Lombardi Comprehensive Cancer Center Support grant number P30CA051008. Manuscript preparation was also supported in part by a scholarship from The Mary Elizabeth Groff Surgical Medical Research and Education Charitable Trust. The study sponsors had no role in the study design; in the collection, analysis and interpretation data; in the writing of the report; and in the decision to submit the paper for publication. The content is solely the responsibility of the authors and does not necessarily represent the official views of the $\mathrm{NIH}$ or the FDA.

\section{Availability of data and materials}

Study materials are available on request from the corresponding author.

\section{Authors' contributions}

DM conceptualized the study, developed the protocol, supervised data collection, conducted statistical analyses, and drafted the manuscript. CS assisted with data collection and drafting of the manuscript. ACJ assisted with data collection and drafting of the manuscript. KPT contributed to interpreting the findings and revising the manuscript for important intellectual content. RSN contributed to conceptualizing the study, interpreting the findings, and revising the manuscript for important intellectual content. All authors read and approved the final manuscript.

\section{Competing interests}

The authors declare that they have no competing interests.

\section{Consent for publication}

Not applicable.

\section{Ethical approval and consent to participate}

This study was approved as exempt by the Georgetown University Institutional Review Board. All participants provided informed consent.

\section{Author details}

'Department of Oncology, Georgetown University Medical Center, Lombardi Comprehensive Cancer Center, 3300 Whitehaven St NW Suite 4100, Washington DC 20007, USA. ${ }^{2}$ Schroeder Institute for Tobacco Research \& Policy Studies, Truth Initiative, 900 G Street NW, Washington DC 20001, USA.

\section{Received: 9 February 2016 Accepted: 18 May 2016}

Published online: 26 May 2016

\section{References}

1. Arrazola RA, Singh T, Corey CG, Husten CG, Neff $L$, Apelberg BJ, et al. Tobacco use among middle and high school students - United States, 2011-2014. MMWR Morb Mortal Wkly Rep. 2015;64(14):381-5.

2. Pepper JK, Brewer NT. Electronic nicotine delivery system (electronic cigarette) awareness, use, reactions and beliefs: a systematic review. Tob Control. 2014;23(5):375-84

3. King BA, Patel $\mathrm{R}$, Nguyen $\mathrm{KH}$, Dube SR. Trends in awareness and use of electronic cigarettes among US adults, 2010-2013. Nicotine Tob Res. 2015:17(2):219-27

4. Zhu SH, Gamst A, Lee M, Cummins S, Yin L, Zoref L. The use and perception of electronic cigarettes and snus among the U.S. population. PLoS One. 2013;8(10), e79332
5. Agaku IT, King BA, Husten CG, Bunnell R, Ambrose BK, Hu SS, et al. Tobacco product use among adults-United States, 2012-2013. MMWR Morb Mortal Wkly Rep. 2014;63(25):542-7.

6. Delnevo CD, Giovenco DP, Steinberg MB, Villanti AC, Pearson JL, Niaura RS, et al. Patterns of electronic cigarette use among adults in the United States. Nicotine Tob Res. 2015. doi:10.1093/ntr/ntv237.

7. Kim AE, Arnold KY, Makarenko O. E-cigarette advertising expenditures in the U.S., 2011-2012. Am J Prev Med. 2014;46(4):409-12.

8. Grana RA, Ling PM. "Smoking revolution": a content analysis of electronic cigarette retail websites. Am J Prev Med. 2014;46(4):395-403.

9. Grana RA, Glantz SA, Ling PM. Electronic nicotine delivery systems in the hands of Hollywood. Tob Control. 2011;20(6):425-6.

10. Kim AE, Lee $Y O$, Shafer $P$, Nonnemaker J, Makarenko O. Adult smokers' receptivity to a television advert for electronic nicotine delivery systems. Tob Control. 2015:24(2):132-5.

11. Maloney EK, Cappella JN. Does vaping in e-cigarette advertisements affect tobacco smoking urge, intentions, and perceptions in daily, intermittent, and former smokers? Health Commun. 2015;11:1-10

12. Farrelly MC, Duke JC, Crankshaw EC, Eggers ME, Lee YO, Nonnemaker JM, et al. A randomized trial of the effect of E-cigarette TV advertisements on intentions to use e-cigarettes. Am J Prev Med. 2015. doi:10.1016/j.amepre. 2015.05.010

13. Duke JC, Lee YO, Kim AE, Watson KA, Arnold KY, Nonnemaker JM, et al. Exposure to electronic cigarette television advertisements among youth and young adults. Pediatrics. 2014;134(1):e29-36.

14. Choi K, Fabian L, Mottey N, Corbett A, Forster J. Young adults' favorable perceptions of snus, dissolvable tobacco products, and electronic cigarettes: findings from a focus group study. Am J Public Health. 2012;102(11):2088-93.

15. Mays D, Arrazola R, Tworek C, Rolle I, Neff L, Portnoy D. Openness to using non-cigarette tobacco products among U.S. young adults. Am J Prev Med. 2015;50(4):528-34. doi:10.1016/j.amepre.2015.08.015.

16. Sutfin EL, Reboussin BA, Debinski B, Wagoner KG, Spangler J, Wolfson $M$. The impact of trying electronic cigarettes on cigarette smoking by college students: a prospective analysis. Am J Public Health. 2015; 105(8):e83-9.

17. Deeming Tobacco Products To Be Subject to the Federal Food, Drug, and Cosmetic Act, as Amended by the Family Smoking Prevention and Tobacco Control Act: Restrictions on the Sale and Distribution of Tobacco Products and Required Warning Statements for Tobacco Products. A Rule by the Food and Drug Administration. Available from: https://www.federalregister. gov/articles/2016/05/10/2016-10685/deeming-tobacco-products-to-besubject-to-the-federal-food-drug-and-cosmetic-act-as-amended-by-the. Accessed 10 May 2016

18. Gostin LO, Glasner AY. E-cigarettes, vaping, and youth. JAMA. 2014;312(6):595-6.

19. Gateway to Addiction? A Survey of Popular Electronic Cigarette Manufacturers and Targeted Marketing to Youth [Internet]. 2014. Available from: http://www.durbin.senate.gov/imo/media/doc/Report\%20-\%20ECigarettes\%20with\%20Cover.pdf. Accesses 8 Feb 2016.

20. Sanders-Jackson A, Schleicher NC, Fortmann SP, Henriksen L. Effect of warning statements in e-cigarette advertisements: an experiment with young adults in the United States. Addiction. 2015;4.

21. Lee YO, Shafer PR, Eggers ME, Kim AE, Parvanta SA, Nonnemaker JM. Effect of a voluntary e-cigarette warning label on risk perceptions. Tobacco Regulatory Science. 2016;2(1):82.

22. Brabham DC, Ribisl KM, Kirchner TR, Bernhardt JM. Crowdsourcing applications for public health. Am J Prev Med. 2014;46(2):179-87.

23. Mays D, Moran MB, Levy DT, Niaura RS. The impact of health warning labels for Swedish snus advertisements on young Adults' snus perceptions and behavioral intentions. Nicotine Tob Res. 2015. doi:10.1093/ntr/ntv140.

24. Hall MG, Ribisl KM, Brewer NT. Smokers' and nonsmokers' beliefs about harmful tobacco constituents: implications for FDA communication efforts. Nicotine Tob Res. 2014;16(3):343-50.

25. Magnan RE, Cameron LD. Do young adults perceive that cigarette graphic warnings provide New knowledge about the harms of smoking? Ann Behav Med. 2015;49(4):594-604

26. Mays D, Tercyak KP. Framing indoor tanning warning messages to reduce skin cancer risks among young women: implications for research and policy. Am J Public Health. 2015:11:e1-7.

27. Mays D, Zhao X. The influence of framed messages and self-affirmation on indoor tanning behavioral intentions in 18- to 30-year-old women. Health Psychol. 2015;20. 
28. Biener $L$, Albers AB. Young adults: vulnerable new targets of tobacco marketing. Am J Public Health. 2004;94(2):326-30.

29. Hammond D. Smoking behaviour among young adults: beyond youth prevention. Tob Control. 2005;14(3):181-5.

30. National Center for Chronic Disease Prevention and Health Promotion (US) Office on Smoking and Health. Preventing tobacco use among youth and young adults: a report of the surgeon general. Atlanta: Centers for Disease Control and Prevention; 2012.

31. Trinkets \& Trash [Internet]. 2015. Available from: www.trinketsandtrash.org. Accesses 8 Feb 2016.

32. Hoek J, Gendall P, Eckert C, Rolls K, Louviere J. A comparison of on-pack quitline information formats. Tob Control. 2014. doi:10.1136/tobaccocontrol2014-051820.

33. Mays D, Gilman SE, Rende R, Luta G, Tercyak KP, Niaura RS. Influences of tobacco advertising exposure and conduct problems on smoking behaviors among adolescent males and females. Nicotine Tob Res. 2014;16(6):855-63.

34. Centers for Disease Control and Prevention (CDC). Current tobacco use among middle and high school students-United States, 2011. MMWR Morb Mortal Wkly Rep. 2012;61(31):581-5.

35. Noar SM, Hall MG, Francis DB, Ribisl KM, Pepper JK, Brewer NT. Pictorial cigarette pack warnings: a meta-analysis of experimental studies. Tob Control. 2015:6

36. Kaufman AR, Mays D, Koblitz AR, Portnoy DB. Judgments, awareness, and the use of snus among adults in the United States. Nicotine Tob Res. 2014; 16(10):1404-8.

37. Zhao X, Strasser A, Cappella JN, Lerman C, Fishbein M. A measure of perceived argument strength: reliability and validity. Commun Methods Meas. 2011;5(1):48-75.

38. Arrazola RA, Neff $L$, Kennedy SM, Holder-Hayes E, Jones CD, Centers for Disease Control and Prevention (CDC). Tobacco use among middle and high school students-United States, 2013. MMWR Morb Mortal Wkly Rep. 2014;63(45):1021-6.

39. Coleman BN, Apelberg BJ, Ambrose BK, Green KM, Choiniere CJ, Bunnell R, et al. Association between electronic cigarette use and openness to cigarette smoking among US young adults. Nicotine Tob Res. 2015;17(2):212-8.

40. Hammond D. Health warning messages on tobacco products: a review. Tob Control. 2011:20(5):327-37.

41. Strasser AA, Tang KZ, Romer D, Jepson C, Cappella JN. Graphic warning labels in cigarette advertisements: recall and viewing patterns. Am J Prev Med. 2012;43(1):41-7.

42. Emery LF, Romer D, Sheerin KM, Jamieson KH, Peters E. Affective and cognitive mediators of the impact of cigarette warning labels. Nicotine Tob Res. 2014;16(3):263-9.

43. Dire Warnings by Big Tobacco on E-Smoking [Internet]. 2014. Available from: http://www.nytimes.com/2014/09/29/business/dire-warnings-by-bigtobacco-on-e-smoking-html. Accesses 8 Feb 2016.

44. Smith DM, Bansal-Travers M, O'Connor RJ, Goniewicz ML, Hyland A. Associations between perceptions of e-cigarette advertising and interest in product trial amongst US adult smokers and non-smokers: results from an internet-based pilot survey. Tob Induc Dis. 2015;13(1):14,015. -0039-6. eCollection 2015.

\section{Submit your next manuscript to BioMed Central and we will help you at every step:}

- We accept pre-submission inquiries

- Our selector tool helps you to find the most relevant journal

- We provide round the clock customer support

- Convenient online submission

- Thorough peer review

- Inclusion in PubMed and all major indexing services

- Maximum visibility for your research

Submit your manuscript at www.biomedcentral.com/submit
Biomed Central 